\title{
3D mapping of polycyclic aromatic hydrocarbons, hydroxyl radicals, and soot volume fraction in sooting flames using FRAME technique
}

\author{
Devashish Chorey ${ }^{1} \cdot$ Matthias Koegl $^{2} \cdot$ Prasad Boggavarapu $^{3} \cdot$ Florian J. Bauer $^{2} \cdot$ Lars Zigan $^{2,5} \cdot$ Stefan Will ${ }^{2}$. \\ R. V. Ravikrishna ${ }^{3}$. Devendra Deshmukh ${ }^{1} \cdot$ Yogeshwar Nath Mishra ${ }^{2,4}(\mathbb{B}$
}

Received: 11 June 2021 / Accepted: 21 September 2021 / Published online: 11 October 2021

(c) The Author(s) 2021

\begin{abstract}
We report the three-dimensional (3D) mapping of polycyclic aromatic hydrocarbons (PAHs), soot, and hydroxyl radicals $(\mathrm{OH})$ in ethylene/air diffusion flames. A structured illumination-based frequency recognition algorithm for multiple exposures (FRAME) approach is combined with sample translation to intersect the flame in several two-dimensional planes. The FRAME technique has been used for recording a snapshot of multiple species on a single camera. It relies on extracting the amplitude of spatial modulation of two or more probed species encoded on a single sub-image. Here, the FRAME technique is first applied for simultaneous imaging of PAH by laser-induced fluorescence (PAH-LIF) and soot by laser-induced incandescence (LII). Sequentially, it is employed for simultaneous mapping of OH-LIF and soot-LII. The LII signal is converted to absolute soot volume fraction $\left(f_{v}\right)$ maps using a line-of-sight light extinction measurement. Finally, we have demonstrated the approach for layer-wise 2D imaging of soot volume fraction and averaged 3D mapping of multiple species.
\end{abstract}

\section{Introduction}

The soot emission directly relates to the air-fuel mixing and combustion performance of combustion devices [1]. Polycyclic aromatic hydrocarbons (PAHs) are known to be precursors of soot particles-formed under fuel-rich combustion [2]. Due to their carcinogenic properties, great attention is

Yogeshwar Nath Mishra

Yogeshwar.n.mishra@jpl.nasa.gov

Devashish Chorey

phd1801203001@iiti.ac.in

Matthias Koegl

matthias.koegl@gmx.de

Prasad Boggavarapu

bvvsv.prasad@gmail.com

Florian J. Bauer

Florian.fb.bauer@fau.de

Lars Zigan

lars.zigan@fau.de

Stefan Will

stefan.will@fau.de

R. V. Ravikrishna

ravikris@iisc.ac.in

Devendra Deshmukh

dldeshmukh@iiti.ac.in given to minimize the emission of soot and PAH [3]. The hydroxyl radical $(\mathrm{OH})$ is widely used as a reaction zone and post-oxidation zone marker in combustion research [4]. Therefore, the measurement and analysis of combustion species such as soot, $\mathrm{PAH}, \mathrm{OH}, \mathrm{CH}_{2} \mathrm{O}$, etc. [5-7] augment the fundamental understanding of soot formation and validation of predictive models. In particular, two-dimensional

Spray and Combustion Laboratory, Department of Mechanical Engineering, Indian Institute of Technology Indore, Indore, Madhya Pradesh 453552, India

2 Lehrstuhl für Technische Thermodynamik (LTT) and Erlangen Graduate School in Advanced Optical Technologies (SAOT), Friedrich-Alexander-Universität Erlangen-Nürnberg (FAU), 91058 Erlangen, Germany

3 Department of Mechanical Engineering, Indian Institute of Science, Bangalore, Karnataka 560012, India

4 Present Address: NASA-Jet Propulsion Laboratory, California Institute of Technology, Pasadena, CA 91109, USA

5 Present Address: Institut für Thermodynamik, Universität der Bundeswehr München, Werner-Heisenberg-Weg 39, DE-85577 Neubiberg, Germany 
(2D) and/or three-dimensional (3D) optical measurements will help to better "track" and access the local and global distribution of the species in a flame [7].

Laser sheet imaging has been used for 2D mapping of flame species using laser-induced fluorescence (LIF) of hydroxyl radicals $(\mathrm{OH})$ and PAHs or laser-induced incandescence (LII) of soot particles [8]. It can be extended to 3D imaging by intersecting the measurement volume in several 2D planes like "bread-slicing". For instance, 3D mapping of oxygen was conducted in a steady flame in Ref. [9], biacetyl fluorescence in a turbulent premixed flame of $\mathrm{CH}_{4} / \mathrm{air}$ in Ref. [10] where the sample of interest is rapidly scanned by the laser sheet using a mirror often driven by a galvo motor. Similarly, Hult et al. [11] employed the scanning mirror with several high-speed cameras to obtain quantitative $3 \mathrm{D}$ soot volume fraction distributions. Wellander et al. [12] reported a dual-mirror scanning system to obtain timeresolved 3D image sequences of the $\mathrm{OH}$ and the flame front of a premixed flame. Using this approach, non-uniformities in the laser sheet and laser absorption in the flame were compensated and the position- as well as time-dependent $\mathrm{OH}$ concentration was deduced throughout the measurement volume. The method was employed for high-repetition-rate 3D OH imaging of gelled propellant combustion [13]. In another 3D imaging approach, the laser sheet and a camera are kept static while the sample of interest is moved on a translational stage with a step size of $\sim 500 \mu \mathrm{m}$. For example, in non-combusting sprays, three-dimensional (3D) mapping of droplet size [14], liquid volume fraction [15], and extinction-coefficient [16] were conducted. This 3D technique is limited to averaged imaging and does not require a high-speed framing camera as utilized in Refs. [11, 12]. Other optical methods for 3D tomographic reconstruction of soot and radicals using several cameras and optical fibers have been extensively reported in the literature $[17,18]$. Further, 4D imaging of combustion species is reported recently, which provides deeper insight into the spatiotemporal evolution of combustion [19-21]. Nonetheless, the quantification of the combustion process often requires the temporal correlation of multiple species generated in the flame-and simultaneous optical detection of several species is necessary [6, 22-24]. In planar imaging, usually, two chemical species are recorded individually on two cameras in combination with two optical filters (for separating optical signals). Sometimes an "image doubler" is used with a camera to split the full sensor of the camera into two sub-images, which could compromise the pixel resolution [25]. Therefore, in general, simultaneous planar imaging of multiple species requires multiple cameras, laser systems, image intensifiers, and additional optical components-making the optical setups complex and cost-intensive [4, 26, 27]. Furthermore, the quantitative laser sheet measurements in practical combustion devices are often accompanied by unwanted background signals such as scattering, reflections at windows and flame luminosity, and some spectral interference of optical signals, i.e., fluorescence and chemiluminescence from multispecies [28]. This unwanted background signal on top of the probed species spectra is often referred to as "stray light" and can contribute to errors in quantitative measurements [29].

The FRAME (frequency recognition algorithm for multiple exposures) technique has recently been reported to suppress the stray light intensity and to demonstrate a single camera-based multispecies planar imaging setup [30]. For example, multispecies imaging-OH-LIF and $\mathrm{CH}_{2} \mathrm{O}$-LIF [30], instantaneous 3D mapping of $\mathrm{CH}_{2} \mathrm{O}-\mathrm{LIF}$ [31], and very recently qualitative PAH-LIF/LII and OH-LIF/LII imaging in flames [32] have been conducted. Other experiments using the FRAME approach can be found elsewhere [33-36]. The technique relies on only preserving the amplitude of laser-excited signals which is spatially modulated and is the only signal of interest. The background signal or stray lights (non-modulated signal) is suppressed during image post-processing. In this process, we generate an image with a very minor loss in the original spatial resolution of the unprocessed image. Nevertheless, this loss can be made unnoticeable by probing the sample with an incident modulation frequency that is fully resolvable by the objective and is within the Nyquist limit. In FRAME, the spatial modulation is usually achieved by introducing a transmission Ronchi grating in the path of the conventional laser beam of homogenous intensity. The other means to spatially modulate the laser beam can be a digital micromirror device (DMD) [37] or a two-faceted optical component [38]. In FRAME, judiciously, each "coded" illumination probing a different species is sent from different angles towards the incident plane (usually cross-patterned for two species) for probing the sample (see Fig. 1). This arrangement of the incident laser sheets ensures placing each individually "coded" optical signals $\left(\mathrm{OH}-\mathrm{LIF}\right.$ and $\mathrm{CH}_{2} \mathrm{O}-\mathrm{LIF}$, PAH-LIF and LII, OH-LIF and LII) at a different location in Fourier space (frequency domain). For simplicity, fluorescence signals of different species are abbreviated as "OH", "PAH", and LII-signals as "soot", respectively, throughout the paper. Through computational analysis using a spatial lock-in frequency algorithm, two optical signals are separated from the single cross-patterned sub-image (see more [30, 32]).

Recently, we have used two spatially modulated laser sheets of wavelengths $283.5 \mathrm{~nm}$ and $532 \mathrm{~nm}$, aligned in two different directions to excite two different species [32]. The two-modulated optical signals (LIF and LII) corresponding to either $\mathrm{PAH} / \mathrm{soot}$ or $\mathrm{OH} / \mathrm{soot}$ (using a different optical filter) were acquired on a single camera (utilizing the full sensor area). The modulated image was post-processed using the lock-in algorithm to deduce two individual LIF and LII images from a single image. In very recent work, Bao 


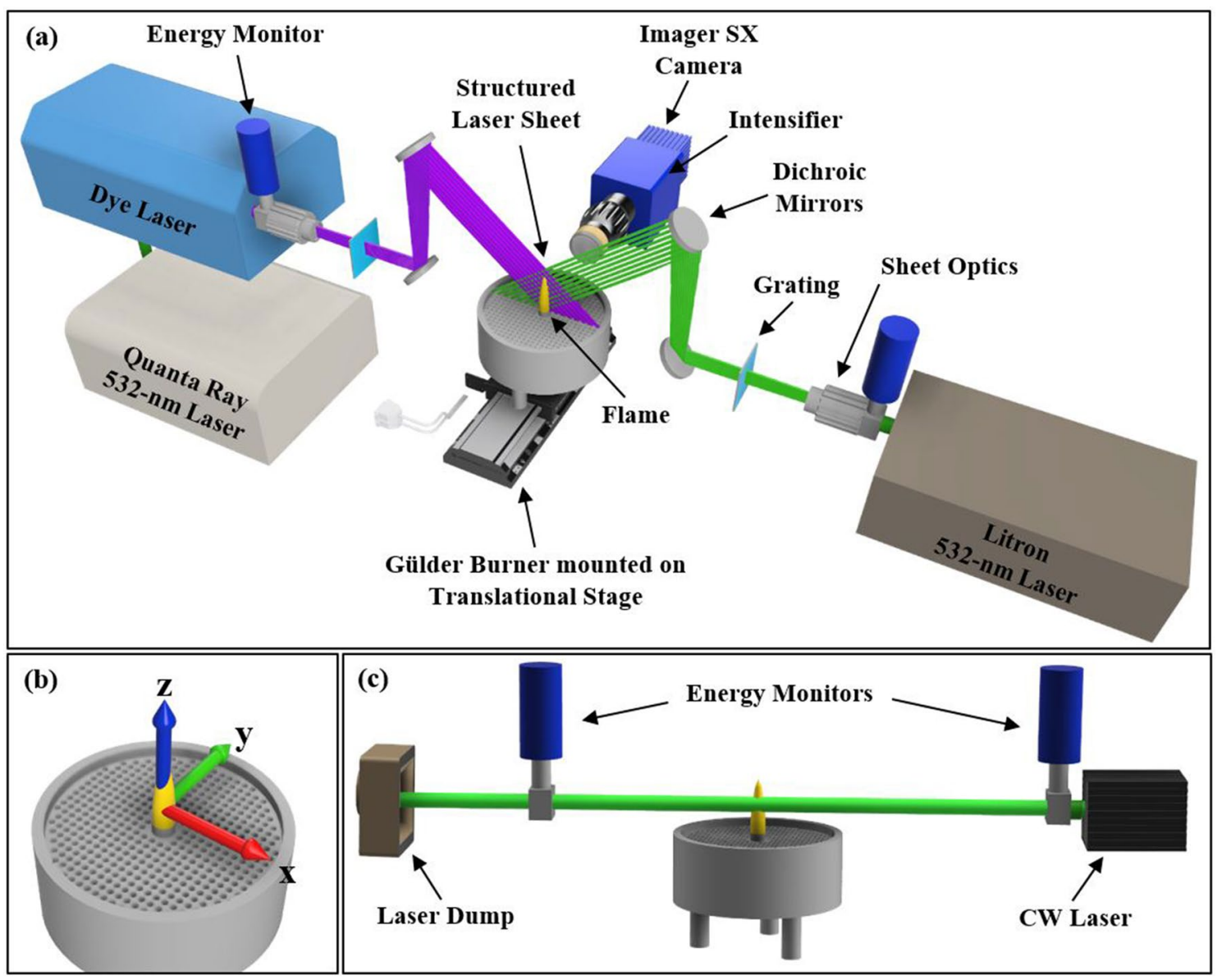

Fig. 1 a Schematic of the 3D scanning FRAME setup for simultaneous LIF and LII imaging, b coordinate system representation on flame and burner surface, and c schematic for the line-of-sight soot

et al. have employed the FRAME technique for single-shot $3 \mathrm{D}$ imaging of $\mathrm{OH}$ radicals in the vicinity of the gliding arc [39]. In their FRAME setup, four structured laser sheets and a single camera were used to achieve the 3D snapshots of a single species. The imaging system suppressed the unwanted plasma emissions and $\mathrm{OH}$ chemiluminescence using this "coded" approach and managed to extract maps of laser-induced fluorescence of $\mathrm{OH}$ radicals. The 3D measurements are ideal to fully describe the 3D features of the probed species and its interactions with the surrounding species, which is insufficient in two-dimensional imaging of the species (probing only a single plane). Therefore, in this article, we have combined the FRAME technique and laser sheet scanning [14] for averaged 3D mappings of multiplespecies pairs: (i) $\mathrm{PAH}$-soot and (ii) $\mathrm{OH}$-soot, sequentially. Here, the laser sheet intersects the various sections of the flame in a "bread slicing manner"-resulting in 2D matrices of the probed planes. During the post-processing, these 2D matrices are "stitched" to reconstruct a 3D map. Note that each single-shot FRAME image of the 2D plane records two extinction measurement using a CW laser. The laser beam overlaps with the laser sheet plane to calibrate planar LII using the laserextinction measurements (not to scale)

species simultaneously on the camera, however, 3D maps are generated from the averaged images of several single-shots for each plane. The LII images are calibrated here with a soot-extinction method to deduce the soot volume fraction, $f_{v}$ (see Subsect. 2.2). This 3D visualization method is demonstrated for the detailed spatial evolution of two chemical species probed simultaneously, which are distributed in symmetric and asymmetric ethylene/air flames.

\section{Background}

\subsection{PAH-LIF and OH-LIF imaging}

Planar laser-induced fluorescence (PLIF) is a non-intrusive technique for measuring distributions of selected species in a 2D plane [40]. In this method, a laser beam is converted into a laser sheet of thickness typically around $0.5 \mathrm{~mm}$ using a combination of cylindrical and spherical lenses and aligned with the target plane of measurement. A specific wavelength 
of the laser is selected for the detection of a particular species based on its absorption and fluorescence characteristics. The molecules of the specific species in the laser sheet plane will absorb the laser photons and may re-emit red-shifted fluorescence. The re-emitted light is captured on a camera placed in a perpendicular direction to the laser sheet. With proper calibration, the species distribution can be quantified. The high sensitivity of the technique is suitable for the detection of radicals and molecules in transient combustion processes [8, 40]. For example, Tanahashi et al. [41] utilized a dye laser generating $5 \mathrm{~mJ} /$ pulse with $8 \mathrm{~ns}$ pulse width emitting $282.93 \mathrm{~nm}$ wavelength for OH-LIF measurements in a methane-air turbulent premixed flame. The $\mathrm{OH}$ fluorescence is observed in a bandwidth of 305-320 nm collected using an intensified CCD camera fitted with an appropriate optical filter. For the characterization of flame in terms of PAH, Kazuhiro et al. [42] used PAH-LIF to visualize it by forming a thin laser sheet of thickness $400 \mu \mathrm{m}$ for $2 \mathrm{D}$ imaging at an excitation wavelength of $283 \mathrm{~nm}$. A narrow band-pass filter ( $\mathrm{FWHM}=10 \mathrm{~nm}$ ) of central wavelength $450 \mathrm{~nm}$ was used to define the emission band. Further details on PAH detection are given in Subsect. 3.1.2.

\subsection{Laser-induced incandescence}

Laser-induced incandescence is based on the principle of heating an ensemble of soot particles by a short laser pulse and detecting the subsequent black body radiation signal [43]. At sufficiently high pulse energies the incandescence signals are almost proportional to the particle concentration [44], and it is commonly used for the determination of $f_{v}$ in pointwise-, 2D- or even 3D-measurements [17]. For soot, the particles are heated close to sublimation temperature of approx. $4000 \mathrm{~K}[45,46]$. Soot volume fraction directly relates to flame temperature field and radiative characteristics as it is a function of the species density and particulate size. The line-of-sight laser extinction method has been widely used for the calibration of LII measurements to obtain absolute values for $f_{v}[46,47]$. It is based on Beer-Lambert's law and the measurement of the attenuation of light passing through an absorbing medium and relating it to the integral of LII signals along this line.

The beam intensity after passing through the medium is described by

$I=I_{0} \exp \left(-\int_{0}^{L} k(l) d l\right)$,

where $L$ is the path length of the beam in the flame, which is equal to the flame diameter $d$ at the HAB position and $k(l)$ is the extinction coefficient at the position $l$. The averaged extinction coefficient $K_{\mathrm{LE}}$ is determined by
$K_{\mathrm{LE}}=\frac{1}{L} \cdot \int_{0}^{L} k(l) d l$.

The soot volume fraction $f_{v}$ [43] can be determined by

$f_{v}=\frac{K_{\mathrm{LE}} \lambda}{6 \pi E(\tilde{m})}$,

where $\lambda$ is the wavelength of the laser light and $E(\tilde{m})$ is the soot absorption function, which can be calculated from the soot refractive index $\tilde{m}$ by

$E(\tilde{m})=-\operatorname{Im}\left(\frac{\tilde{m}^{2}-1}{\tilde{m}^{2}+2}\right)$,

where Im is the imaginary part $[25,48,49]$. The value of $\tilde{m}$ is dependent on the wavelength $\lambda[50]$ and on the soot maturity [51], since their structures and composition change with increasing residence time. Therefore, the value of $\tilde{m}$ varies for different $\mathrm{HAB}$ [52], in this work the common value $\tilde{m}$ $=1.57-0.56 i$ was used $[53,54]$. As the attenuation of the beam intensity is affected by scattering and absorption, the resulting $f_{v}$ values are slightly overestimated by neglecting scattering [25]. As shown by Sorensen et al. [55], however, this error will hardly exceed $10 \%$ for typical soot particles and aggregate sizes.

The LII measurements are calibrated using the extinction data above and considering that the integrated $f_{v}$ across the flame at a particular height above burner (HAB) yields the total projected signal (sum of intensity values along the laser path) as $S_{0}$. Assuming that the optical properties are constant along the path in the whole flame, $S_{0}$ can be considered to be linearly related to the $f_{v}$ using $K_{e}$.

$S_{0}=K_{e} f_{v}$.

More details of the LII imaging are given in Subsect. 3.1 and LII signal conversion to $f_{v}$ using laser-extinction measurements is provided in Subsect. 3.2.

\section{Experimental method and procedure}

\subsection{Optical setup}

\subsubsection{Simultaneous excitation of LIF and LII}

The optical arrangement of the FRAME setup is shown in Fig. 1a, the coordinates in references to the burner are indicated in Fig. 1b, and the LII calibration using laserextinction measurements is given in Fig. 1c. In Fig. 1a, a dye laser (PrecisionScan, Sirah Lasertechnik GmbH, Germany, wavelength: $283.5 \mathrm{~nm}$,) was used for LIF excitation, which was pumped by a pulsed Nd:YAG laser (Quanta Ray, 
FRAME Cross pattern Sub-image

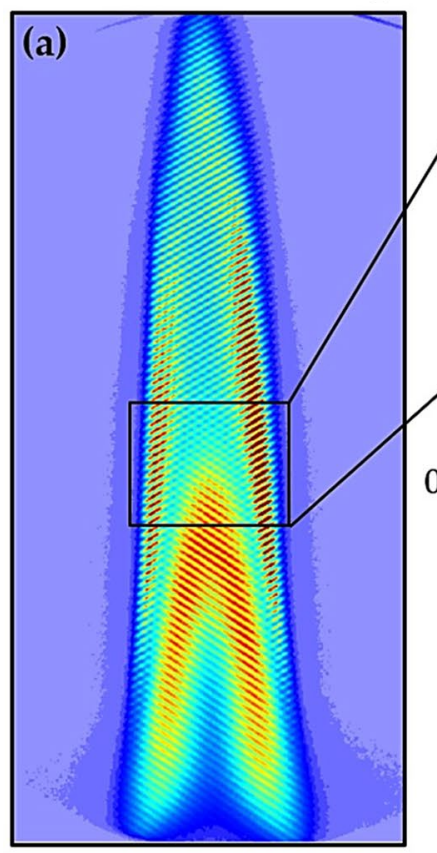

PAH-LIF/Soot-LII intensity modulation

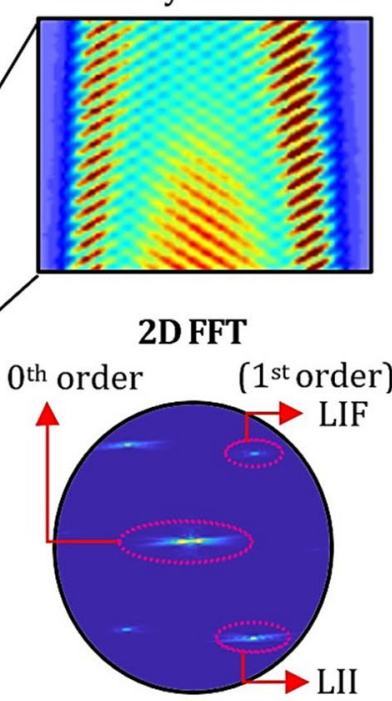

(1 $1^{\text {st }}$ order $)$
Soot-LII

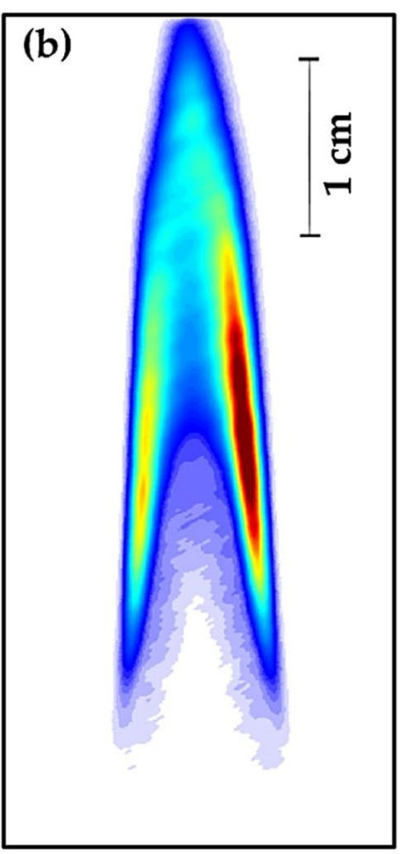

PAH-LIF

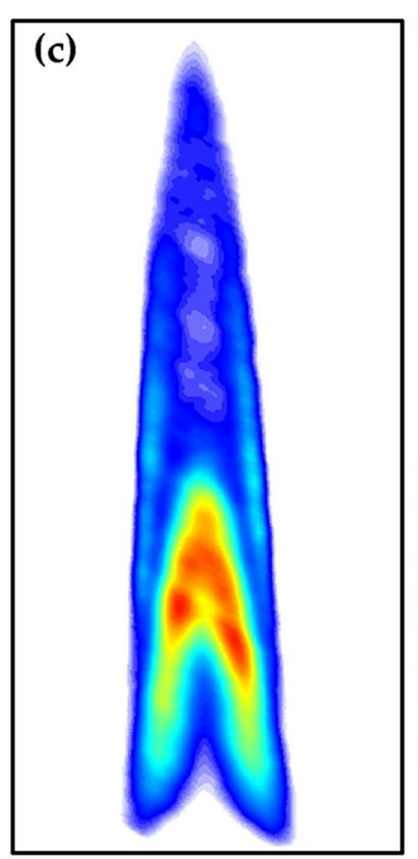

Fig. 2 a Averaged FRAME raw image for the symmetric flame scan (central plane): cross patterned sub-image, zoomed-view of the modulated optical signals, and 2D FFT showing the frequency components of PAH-LIF and soot-LII signals; $b$ processed averaged sootLII image, and c processed PAH-LIF image of the flame, extracted by applying the lock-in algorithm in (a). Note that the raw image in (a) is with background light, which is naturally suppressed in (b) and (c) after image post-processing. The extinction of laser is seen in the flame from the right to left in (b) and from the left to right in (c)
Spectra-Physics Inc., USA, wavelength: $532 \mathrm{~nm}$, pulse width: $10 \mathrm{~ns}$, repetition rate: $10 \mathrm{~Hz}$ ). A second laser (NanoPIV, Litron lasers, UK, wavelength: $532 \mathrm{~nm}$, pulse width: $10 \mathrm{~ns}$ ) was used for the LII measurements. Two similar laser sheet forming units (UV and VIS models, LaVision GmbH, Germany) were used to form the respective laser sheets. Two dichroic mirrors of 2-inch diameters were used to achieve an orthogonal geometry of the cross-patterned light sheets. As mentioned earlier, the laser sheets were kept orthogonal or cross-patterned (X) to each other (see Fig. 1) on purpose for a clean extraction of the first order (amplitude of modulation) from the Fourier plane by placing the two excited signals of interest, LIF and LII at different locations (see Fig. 2). The laser fluence was monitored and recorded with two identical energy meters (Models: VZ15-0070, LaVision $\mathrm{GmbH}$, Germany), which were inserted between the sheet optics setups and the laser source. A nearly top-hat beam profile was maintained with the help of an iris inserted before the sheet forming optics setup and measuring the beam profile.

Two custom-made transmission gratings were used for the spatial modulation of the laser sheets. As commercially available float glass gratings absorb ultra-violet light radiation ( $283.5 \mathrm{~nm}$ wavelength laser), a ten linepairs $/ \mathrm{mm}$ grating $(2$-inch $\times 2$-inch) was used, which was custom manufactured using a quartz substrate. The overlapped region formed by the guided modulated light sheets was approximately $50 \mathrm{~mm}^{2} \times 50 \mathrm{~mm}^{2}$, which was sufficient to cover the flame dimensions. The laser sheet thickness was approximately $0.5 \mathrm{~mm}$. Here, PAH-LIF/soot-LII and OH-LIF/soot-LII excitations were performed sequentially. Note that for the detection of PAH and $\mathrm{OH}$ two different optical filters were used (see Subsect. 3.1.2). The averaged laser fluences at the incident plane for the flame scanning were $\sim 0.012 \mathrm{~J} / \mathrm{cm}^{2}$ for the $283.5 \mathrm{~nm}$ laser and $\sim 0.28 \mathrm{~J} / \mathrm{cm}^{2}$ for the $532 \mathrm{~nm}$ laser. The laser fluences were maintained the same for both PAH-LII and OH-LII experiments. The pulse-to-pulse laser energy variation was around $7.5 \%$ and within $1 \%$ for the $283.5 \mathrm{~nm}$ and $532 \mathrm{~nm}$ wavelength laser, respectively. Throughout the experiments, the average laser fluence for LII lied within the plateau region of the LII-fluence plot [48]. Note that the non-linear aspect between LII signal and illumination intensity relation was not considered in this study, which is discussed elsewhere $[56,57]$. For example, in nonlinear structured illumination microscopy, Gustafsson [56] has reported that in a case where the emitted signal depended nonlinearly (saturated fluorescence) on the illumination intensity, a twice as high resolution can be achieved. Similar work using structured laser sheet illumination has been reported by Kristensson 
[57] for saturated fluorescence of nitric oxide in a laminar flow. It leads to the generation of higher harmonics in a spatially modulated image (2nd order peaks in FFT), and "sharper" modulation depth, which could produce images with pronounced spatial resolution. More details on linearnonlinear signal detection are given in Subsect. 4.6.

\subsubsection{Simultaneous detection of LIF-LII signals}

For the detection of modulated LIF/LII optical signals, an ultra-violet macroscopic objective (Serial No.: VZ140975, LaVision GmbH, Germany, 100 mm, f \# 2.8) coupled with an image intensifier (Serial No.: VC15-0030, LaVision $\mathrm{GmbH}$, Germany, 5 ns gate) and an sCMOS camera (Imager SX, LaVision GmbH, 12-bit, 1776×2360 pixels) were used. The yielded pixel resolution was 40 pixels per millimeter. Lasers and camera are synchronized and images were recorded using DaVis 8.1 software (LaVision $\mathrm{GmbH}$, Germany). For the first measurement of PAH and soot, the wavelength of $283.5 \mathrm{~nm}$ (from laser 1) was used to excite the fluorescence from PAH while a wavelength of $532 \mathrm{~nm}$ (from laser 2) was used to heat the soot particles. A spectral bandpass filter (360-430 nm, LaVision GmbH, Germany) was used to collect both signals together. Similarly, for the second measurement of $\mathrm{OH}$ and soot, the wavelength of $283.5 \mathrm{~nm}$ (from laser 1) was used to excite the fluorescence from $\mathrm{OH}$ while a wavelength of $532 \mathrm{~nm}$ (from laser 2) was used for LII. A spectral bandpass filter (305-315 nm, LaVision GmbH, Germany) was used to collect both signals, which also deliberately blocked the emission wavelength signal from PAH (excited by the same wavelength of $283.5 \mathrm{~nm}$ ). PAH signals for aromatics with up to four rings can be detected with the fluorescence signal between 360 and $430 \mathrm{~nm}$. The laser pulse emission was observed to have a delay of around $150 \mathrm{~ns}$ after the trigger from the timing unit. Thus, the intensifier was set with a $150 \mathrm{~ns}$ delay and a gate of $350 \mathrm{~ns}$ to collect both fluorescence (which lasts for a few nanoseconds) and incandescence signals (which last for few hundreds of nanoseconds) after the laser pulse. The possible signal interferences and their isolation/suppression in our experiments are discussed in Subsect. 4.5 and further in Appendix A.

\subsubsection{Burner specifications and laser sheet scanning of the flame}

For 3D scanning, a standard laminar diffusion burner (commonly referred to as "Gülder" burner) was used as it is well characterized in terms of $f_{v}$. The burner design includes a laminar airflow surrounding the fuel outlet, which helps to stabilize the flame and shields the flame from its surrounding [46]. The airflow was homogenized by a layer of numerous small steel balls and a layer of honeycomb mesh.
The annular guard flow duct was of diameter $100 \mathrm{~mm}$. For obtaining an asymmetric flame, a swirler of a diameter of $30 \mathrm{~mm}$ equipped with five blades with a $45^{\circ}$ blade angle was placed on the fuel nozzle. The photographs of both symmetric and asymmetric flames are provided in Appendix A (in Fig. 6). For 3D mapping, the burner was mounted on a linear translational stage for laser sheet scanning of the flame (scan step: $0.5 \mathrm{~mm}$ ). Scanning the symmetric flame required 16 layers whereas scanning the asymmetric flame requires 53 scans for completely capturing the entire flame. A total of 300 single-shot images were taken for each scan, which was averaged during post-processing. Note that each single-shot image acquires the data of two chemical species recorded simultaneously from the same plane of the flame. The fuel flow rate was 0.15 SLPM for the symmetric flame and 0.35 SLPM for the asymmetric flame. The air flow rate was kept at 160 SLPM. The flow rates were selected to achieve a highly sooty flame and a flame height of $\sim 45 \mathrm{~mm}$ above the nozzle for symmetric and above the swirler for the asymmetric flame.

\subsection{Calibration of LII signals}

The calibration for obtaining $f_{v}$ values for the LII images was done by performing laser extinction measurements as described in Subsect. 2.2. A continuous-wave diode laser (532 nm, see Fig. 1c) with a beam diameter of $3 \mathrm{~mm}$ was used with two laser energy monitors to measure the lineof-sight extinction of the laser beam. The laser beam was aligned to pass through the flame at $20 \mathrm{~mm}$ above the burner. The fluence of the laser beam is measured before and after the flame. The initial $\left(I_{0}\right)$ and final intensity $(I)$ values (see Eq. 1) were averaged from three separate measurements. The calibration position ( $Y=0 \mathrm{~mm}$, see Fig. 4) can be identified from the images for individual scans $(Y=-7-8 \mathrm{~mm})$ in the symmetric flame. The $f_{v}$ values were in agreement with the literature for approximately similar parameters and settings $[48,54]$. The mean value of $f_{v}$ was obtained from an averaged LII image, which was obtained by averaging 300 images to account for slight variations in the flame shape. The same calibration data were applied for both symmetric and asymmetric flames.

\section{Results and discussion}

\subsection{Simultaneous soot-LII and PAH-LIF images}

Figure 2a shows the raw unprocessed averaged image (from 300 single-shot images) at the central plane consisting of modulated PAH-LIF and soot-LII signals along with the zoomed view of the crossed patterns. A detailed description of the computational post-processing procedure to 
extract individual optical signals from a snapshot FRAME image is given in our recent work [32] and in Ref. [30]. The background signal in the raw image is retained in Fig. 2a on purpose to demonstrate that it is naturally suppressed after image post-processing. The corresponding processed images for isolated LII and PAH are given in Fig. 2b and c, respectively. The image contrast of the processed images is enhanced compared to the unprocessed image since the FRAME approach suppresses the stray light and background radiation intensities (see also Sect. 4.5). Similarly, the enhancement in the contrast of this method in comparison to the conventional approach (homogeneous laser sheet) is reported in Ref. [32].

Nevertheless, as mentioned before, in the processed images, there is a minor or unnoticeable loss in the original spatial resolution. Here, the color maps of the images are non-normalized and individually intensity-adjusted to pronounce the visualization of the corresponding species. When comparing (b) and (c), PAH is mostly observed in the primary combustion zone, which is the inner core area of the flame, and soot is found in the secondary combustion zone, which is the outer region of the flame. In the secondary combustion zone, the PAH and soot coexist together. The first soot signal intensities can be detected at a certain flame height from the nozzle, see also the other planes (Fig. 3) and 3D reconstructed images below (Fig. 4). The extinction of laser light is visible (from right to left) in the LII image. However, the PAH signal shows less extinction in comparison to LII. Note that the data presented here are qualitative and quantification is only performed for the LII images using a line-of-sight extinction method (see Subsect. 3.2), which is presented in the later sections.

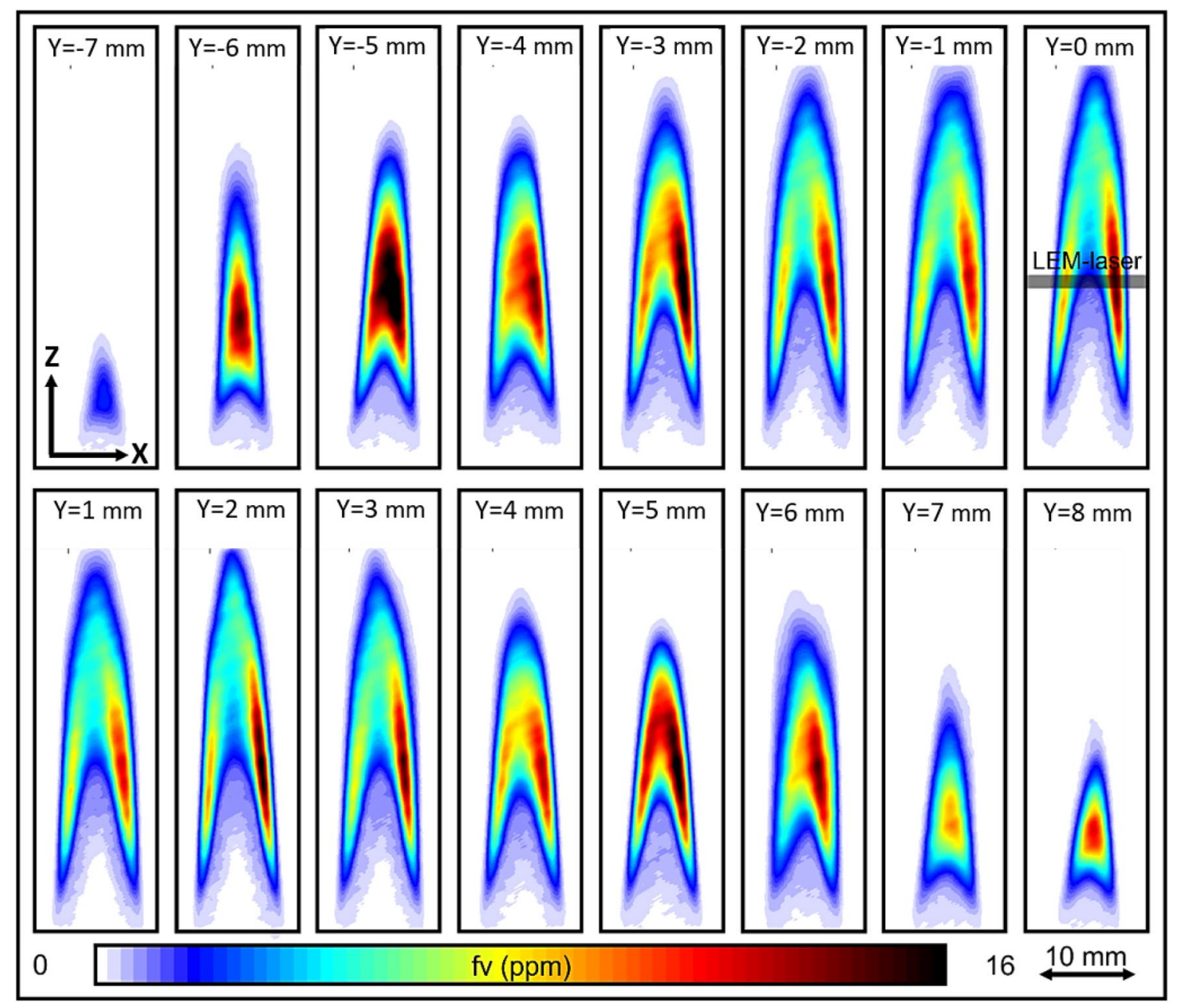

Fig. 3 Demonstration of layer-wise 2D sectioning of the flame: averaged soot-volume fraction images for symmetric flame scans from $Y=-7$ to $8 \mathrm{~mm}$. The measurement area for LII calibration to determine $f_{v}$ using laser-extinction measurement (LEM) is highlighted as a bold black line at $Y=0 \mathrm{~mm}$. This provides a detailed overview of the probed species spatial variation layer-wise which is often difficult to deduce from a single plane image 


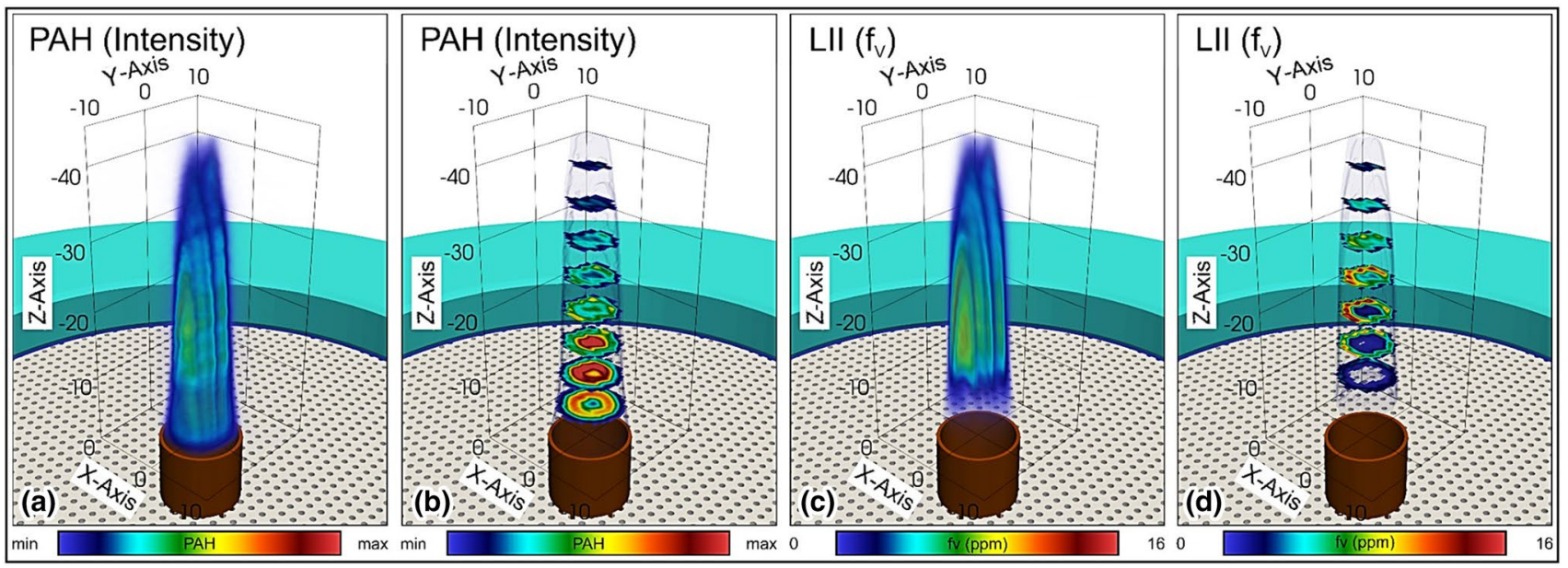

Fig. 4 The 3D reconstructed images of symmetric flame for simultaneous PAH-LIF $(\mathbf{a}, \mathbf{b})$ and $f_{v}$ detection $(\mathbf{c}, \mathbf{d})$. The vertical crosssections of the two species in flame in (a) and (c) and horizontal

\subsection{Layer-wise 2D images of soot volume fraction $\left(f_{v}\right)$}

Figure 3 shows the 2D maps of absolute $f_{v}$ for individual symmetric flame probed by the laser sheet at different planes from $Y=-7$ to $8 \mathrm{~mm}$. Light extinction in soot images is observed to increase along with increasing beam travel path length. The $f_{v}$ range obtained is in accordance with the literature providing values of maximal $f_{v}=14.8 \mathrm{ppm}$ for approximately similar flame and conditions [48]. The extinction effects dominate the differences between the left and right sides of the $f_{v}$ gradients of the axis-symmetric flame. The change in some scans showing an irregular change in flame height instead of progressive increase or decrease is due to some axis asymmetry between the right and left side of the flame observed from the averaged flame intensity image (recorded without laser illumination) [32]. This asymmetry can also be due to the weak flickering of the flame moving sideways and appears to be more pronounced due to the laser extinction effects.

\subsection{D-mapping of symmetric flame}

Figure 4 provides an overview of the results of the 3D reconstruction of the symmetric flame from 16 closely spaced $2 \mathrm{D}$ scans ( $Y=-7-8 \mathrm{~mm}$, see Fig. 3). Two different representations in Fig. $4 \mathrm{a}$ and b for PAH and Fig. $4 \mathrm{c}$ and $\mathrm{d}$ for $f_{v}$ are shown for a clearer and detailed visualization. Figure $4 \mathrm{a}$ and $\mathrm{c}$ are full flame visualization for an overview of the presence of investigated species (here $R$ is considered as the radial distance in $X, Y$ plane from the $Z$-axis along which the flame is symmetrical for explanatory purpose). Figure $4 b$ and $d$ are horizontal cross-sectional planes (along $Z$-axis from $Z=0$ to cross-sections of species in (b) and (d) present the detailed internal structure and local distribution. The photograph of the flame is given in Appendix A in Fig. 6

$45 \mathrm{~mm}$ where $Z$ also represents the HAB). From PAH-LIF intensity images, we can observe that the presence of $\mathrm{PAH}$ starts immediately from the nozzle exit at $\mathrm{HAB}=0 \mathrm{~mm}$. The intensity increases and reaches a maximum at $\sim 10 \mathrm{~mm}$ $\mathrm{HAB}$ after which a continuous decrease can be observed while moving towards the top of the flame. Radially, PAH can be observed to be increasing from $R=0$ to $5 \mathrm{~mm}$ and then decreasing towards $R=10 \mathrm{~mm}$. The $f_{v}$ images show a near nozzle absence of soot from $\mathrm{HAB}=0$ to $5 \mathrm{~mm}$. A very small amount of $f_{v}=1-5 \mathrm{ppm}$ is observed between 10 and $15 \mathrm{~mm} \mathrm{HAB}$, where the PAH signal shows the highest intensities indicating the soot formation region. The highest soot concentration $\left(f_{v}=12-18 \mathrm{ppm}\right)$ is observed in the upper flame region ( $\mathrm{HAB}=20-30 \mathrm{~mm}$ ), except in the center of the flame. Radially, increasing soot can be observed from $R=0$ to $10 \mathrm{~mm}$ and the highest concentration is between $R=5$ and $8 \mathrm{~mm}$. It is imperative to note that the PAH intensity is axisymmetric, whereas the LII signal shows decreasing intensities in the $X$-direction due to extinction, see also Fig. 3.

The presented results indicate that a $3 \mathrm{D}$ representation of the PAH and soot formation, as well as oxidation, is much more comprehensive. This is even more evident for complex reactive flows, e.g., the asymmetric flame presented below.

\subsection{D-mapping of asymmetric flame}

Figure 5 shows the vertical (top row) and horizontal (bottom row) cross-sections of 3D maps of the multispecies in an asymmetric flame. In the first measurement, the laser sheet scanning for 3D reconstruction is performed by simultaneous imaging of PAH-LII $\left(f_{v}\right)$ (see Fig. 5a, b). Sequentially, the next measurement is continued for the simultaneous 


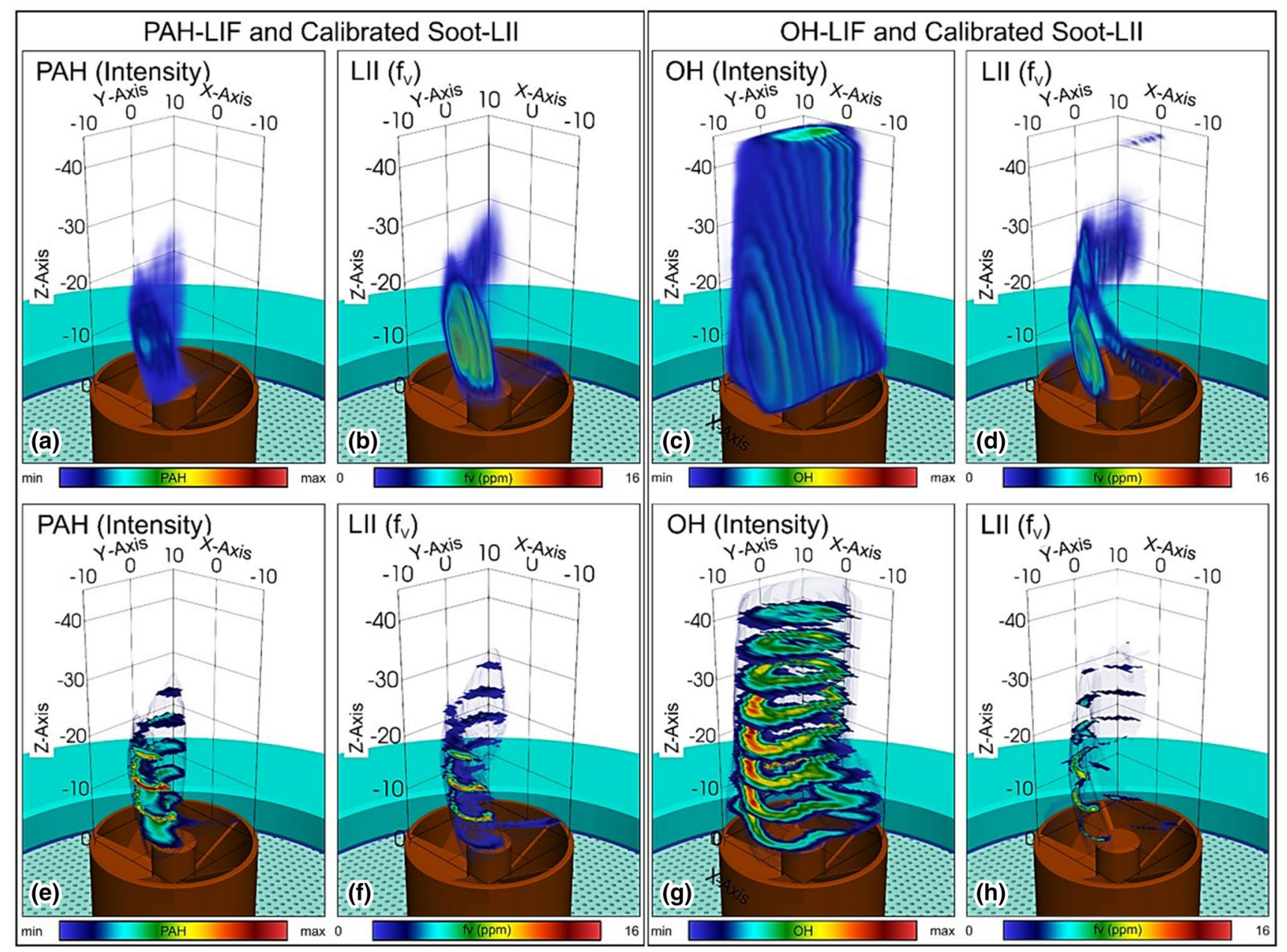

Fig. 5 The 3D reconstructed images for asymmetric flame for simultaneous PAH-LIF (a, e), $f_{v}$ detection $(\mathbf{b}, \mathbf{d}, \mathbf{f}, \mathbf{h})$, and OH-LIF detection $(\mathbf{c}, \mathbf{g})$ are shown. Full flame view reconstructed from the vertical cross-sections of the three species in flame in (a-d) and horizontal cross-sections of species in $(\mathbf{e}, \mathbf{f})$ produces detailed internal struc-

OH-LII $\left(f_{v}\right)$ detection (by changing the optical filter) to perform 3D reconstruction (see Fig. 5c, d). The corresponding horizontal cross-sections at $5 \mathrm{~mm}$ difference are given in Fig. 5e and f for PAH-LII $\left(f_{v}\right)$ and in Fig. $5 \mathrm{~g}$ and $\mathrm{h}$ for OH-LII $\left(f_{v}\right)$. The $f_{v}$ in both measurements shows an average value of 5-12 ppm at $R=10-15 \mathrm{~mm}$. The PAH-LIF and soot signals cannot be detected above $\mathrm{HAB}=30 \mathrm{~mm}$. For $\mathrm{OH}-$ LIF, the maximum signal is observed between $\mathrm{HAB}=10$ and $25 \mathrm{~mm}$. The $\mathrm{OH}$ is absent in the inner cone-like region of the flame. This inner region of the OH-LIF image with an absence of $\mathrm{OH}$ is broader in the zone at around $\mathrm{HAB}=5 \mathrm{~mm}$ and significantly decreases up to $\mathrm{HAB}=40 \mathrm{~mm}$. In the same image, the outer diameter of the $\mathrm{OH}$ species is nearly the same. This may be due to the swirling effect in the flame. In Fig. $5 \mathrm{c}$ and g, OH appears to be more spread out and mostly residing in the outer region of the flame depicting a wider flame caused by its presence in the post oxidation zone. In ture and local distribution. PAH-LII $\left(f_{v}\right)$, OH-LII $\left(f_{v}\right)$ measurements reported here are performed one after another and not simultaneously, therefore a difference in the soot images can be observed. The photograph of the flame is given in Appendix A in Fig. 6

the same region, increased soot production is observed, which is oxidized leading to larger heat release and increased $\mathrm{OH}$ signal. Since the asymmetric flame is having its "major volume" located on one side, the species concentration is significantly different on the LHS and RHS of the flame. Hence, due to the small distance of laser light traveling in high volume regions, the effect of laser extinction is not visible. The extinction effects are also lower when the species concentration is lower. Laser extinction is not corrected in the processing of LII images since it is not in the scope of this work. Nevertheless, it can be done using numerical corrections as used in Ref. [58].

When comparing asymmetric flame images to the symmetric flame images given in Fig. 4, soot and PAH do not show an offset from the burner (flame is not "lifted" in the asymmetric case). The swirler diameter $(30 \mathrm{~mm})$, which was mounted on the nozzle, is larger than the fuel outlet 
(10.9 mm) allowing entrainment of air. Hence, the combustion process is already initiated inside the swirler (and soot deposition is visible on the swirler blades as well). Furthermore, in comparison to the symmetric flame, a significant reduction of the $f_{v}$ can be observed here. However, when comparing the asymmetric flame species, the $f_{v}$ appears slightly different for the PAH-LII and OH-LII. This could be due to higher soot deposition on the swirler blades as the experiment progressed and thus lower $f_{v}$ in the second measurement (which is OH-LII). The soot deposition on the blades could result in changed flow and thermal boundary conditions in the swirler itself and thus variations in the mixing of fuel and air as well as in the soot formation. Note that we wanted to keep the swirler at the same position for both sequential measurements, therefore, the soot deposition on the swirler blades was not cleaned. Nevertheless, the asymmetric flame structures are approximately similar for both data sets (see, e.g., the radial $f_{v}$-distributions).

\subsection{Signal interferences}

The simultaneous measurement of $\mathrm{OH}$ and LII, and $\mathrm{PAH}$ and LII could lead to crosstalk between the respective signals. To analyze the influence of the particle heating caused by the LIF-laser $\left(0.012 \mathrm{~J} / \mathrm{cm}^{2} @ 283.5 \mathrm{~nm}\right)$ on the LII signal, calculations of the particle temperatures and the corresponding LII signals were performed using an LII-model described in detail in Ref. [59]. With the assumption of a primary particle diameter of $25 \mathrm{~nm}$ and an initial gas temperature of $1600 \mathrm{~K}$ (as an average temperature in this type of flame), the simulation revealed that the influence of the LIF-laser on the LII-signal can be neglected (its contribution is $<1 \%$ ).

Although an influence of LII signals on the LIF-detection cannot be completely neglected, it is assumed to be small due to the bandpass wavelength range in the UV, where only a weak LII signal is present [60]. Concerning the crosstalk between both LIF signals, PAHs as precursor molecules are mainly located in the fuel-rich zone before the sooting region, whereas $\mathrm{OH}$ appears at the flame front. Consequently, both LIF signals are spatially separated and the crosstalk of PAH-fluorescence in the $\mathrm{OH}$ signal is not critical because the contribution from $\mathrm{PAH}$ excited by $283 \mathrm{~nm}$ in the detection range of $\mathrm{OH}$ fluorescence filter $(300-315 \mathrm{~nm})$ is not significant. The PAH excited by $283 \mathrm{~nm}$ is reported to be very strong in the $\mathrm{CH}_{2} \mathrm{O}$ excitation $(355 \mathrm{~nm})$ and $\mathrm{CH}_{2} \mathrm{O}$ LIF detection range $( \pm 385 \mathrm{~nm})$. In case of significant $\mathrm{OH}-\mathrm{PAH}$ overlap contributions, the detuning of the $\mathrm{OH}$ wavelength excitation can help to suppress the $\mathrm{PAH}$ intensity contribution in $\mathrm{OH}$. Further, in Ref. [61] it is shown that the fluorescence of PAH and $\mathrm{OH}$ fluorescence are spatially separated. Other concerns could be the detection of chemiluminescence emissions, such as $\mathrm{OH}^{*}, \mathrm{CH}^{*}$, and $\mathrm{C}_{2} *$ in the spectral range of the optical filters used in this study from 300 to $430 \mathrm{~nm}$. Nevertheless, these signals are much weaker in comparison to laser-induced fluorescence and incandescence. Furthermore, the gating time in the range of ns in this experiment will reduce the chemiluminescence interference. More importantly, chemiluminescence can be fully suppressed by the modulation of the signals. For example, using the FRAME technique, $\mathrm{OH}$ chemiluminescence was suppressed in the 3D imaging of OH-LIF [39]. The setup completely suppressed the interference in conditions of $1: 1$ and $6: 1$ ratio between the interference to signals. As mentioned above, the FRAME technique only extracts the amplitude of the modulated signal (generated by the laser sheet) and non-modulated signals are suppressed in the image analysis. Thus, the chemiluminescence contribution can be neglected in this work.

\subsection{Linear-nonlinear signals detection and signal absorption}

The LIF signals are linearly and the LII signal is nonlinearly depending on the laser fluence in our measurements using the FRAME technique. Since this approach stemmed from structured illumination, there are several extensive studies reported already in terms of signal, noise, and resolution [56, 62, 63]. When the fluorescence emissions rate is directly proportional to the excitation intensity (for instance in PAH-OH LIF excitation in our case), the maximum achievable lateral spatial resolution can be a factor of two. It is mainly because the spatial frequencies that can be introduced into the illumination pattern are limited by diffraction as it is for the observable frequencies. However, if the emission rate per fluorophore is a nonlinear function of the illumination intensity (LII signal in our case), the spatial frequency in the Fourier domain will contain the harmonics of the illumination pattern. Therefore, the spatial frequency of the harmonics leads to a much larger increase in resolution. In the present study, we have extracted the amplitude of the $1^{\text {st }}$ order frequency component, therefore, a nearly similar resolution is expected for both LIF and LII detection. For more quantitative analysis, a detailed study is needed, which is beyond the scope of this work. Further, the FRAME technique relies on extracting the amplitude of modulation, therefore, it is difficult to detect the signals from the regions in the flame, where the spatial modulation is not preserved. For example, in Fig. 7c, the modulation depth of PAH-excitation towards the right side of the flame is weaker, thus, the detected signal in Fig. $7 d$ is much lower. Nevertheless, the effects of light extinction and signal attenuation in sooty regions 
are possible to correct using a fluorescence-based experimental approach combined with numerical analysis as done for spray imaging in Ref. [58]. In our measurements in Fig. 2, FRAME can suppress the contribution of stray light in PAH LIF by $48 \%$ (HAB $=5 \mathrm{~mm}, X=0 \mathrm{~mm}$ ) and $11 \%$ ( $\mathrm{HAB}=15 \mathrm{~mm}, X=0 \mathrm{~mm}$ ). In soot LII, the suppression is $27 \%(\mathrm{HAB}=15 \mathrm{~mm}, X=2.5 \mathrm{~mm})$ and $2 \%(\mathrm{HAB}=25 \mathrm{~mm}$, $X=2.5 \mathrm{~mm})$. These calculations are performed according to Ref. [64], where structured illumination intensity (S) is subtracted from the corresponding conventional illumination intensity (C) and the relative amount of light suppression is given as $(\mathrm{C}-\mathrm{S})$ divided by $\mathrm{C}$.

\section{Conclusion}

A single camera-based FRAME technique was combined with laser sheet scanning for layer-wise snapshot 2D imaging of PAH-LII and OH-LII, sequentially, in ethylene/air diffusion flames. The multispecies information is collected in a single exposure using a single detector and extracted in post-processing of the Fourier transform of the recorded image, where each species is located in a distinct region of the Fourier domain. Signal interferences such as chemiluminescence and signal crosstalk are suppressed by the FRAME approach. The averaged 3D maps were reconstructed from several 2D layers generated at different depths in $Y$-direction. The 3D approach is demonstrated to reveal the global distribution of PAH-soot-OH in an asymmetric flame and PAH-soot in an axis-symmetric flame. The approach provides detailed flame structure information to correlate multispecies dispersion during combustion. Especially, the horizontal slices provide deep insights into soot formation and oxidation, which are useful for a better understanding of the sooting combustion process. The measured soot volume fraction $\left(f_{v}\right)$ for the symmetric flame agrees well with literature values. The quality of the 3D images obtained is found to be suitable to resolve flame structure and gradients with an enhanced image contrast. The presented technique enables a cost-effective multi-species 3D imaging scheme for probing a variety of flames. Furthermore, layer-wise 2D snapshot high-speed multispectral imaging is possible using a high-speed camera and laser systems.

\section{Appendix A}

Figure 6 shows the actual photographs of symmetric flame in (a) and asymmetric flame in (b). We applied the FRAME image post-processing on a modulated image of only one species excitation (on a 2D plane different to Fig. 2) to confirm that the isolation of signal components avoids signal interferences in Fig. $2 b$ and c. For example, first, we recorded soot-LII and then PAH-LIF by blocking one laser, sequentially. Figure $7 \mathrm{a}$ and $\mathrm{c}$ show the unprocessed images of only soot-LII and only PAH-LIF, respectively. The 2D FFTs of these two images are in the middle of Fig. 7. The single excitation generates the first-order peaks only corresponding to one species in the Fourier domain. Figure $7 \mathrm{~b}$ and $\mathrm{d}$ are the processed images of LII and LIF, respectively. The images in (a) and (c) are reconstructed from 400 singleshots to enhance the species visibility in the probed plane. The PAH signal on the right side of the flame in (d) is lower compared to the left side because the modulation depth in the laser sheet in (c) is weaker.
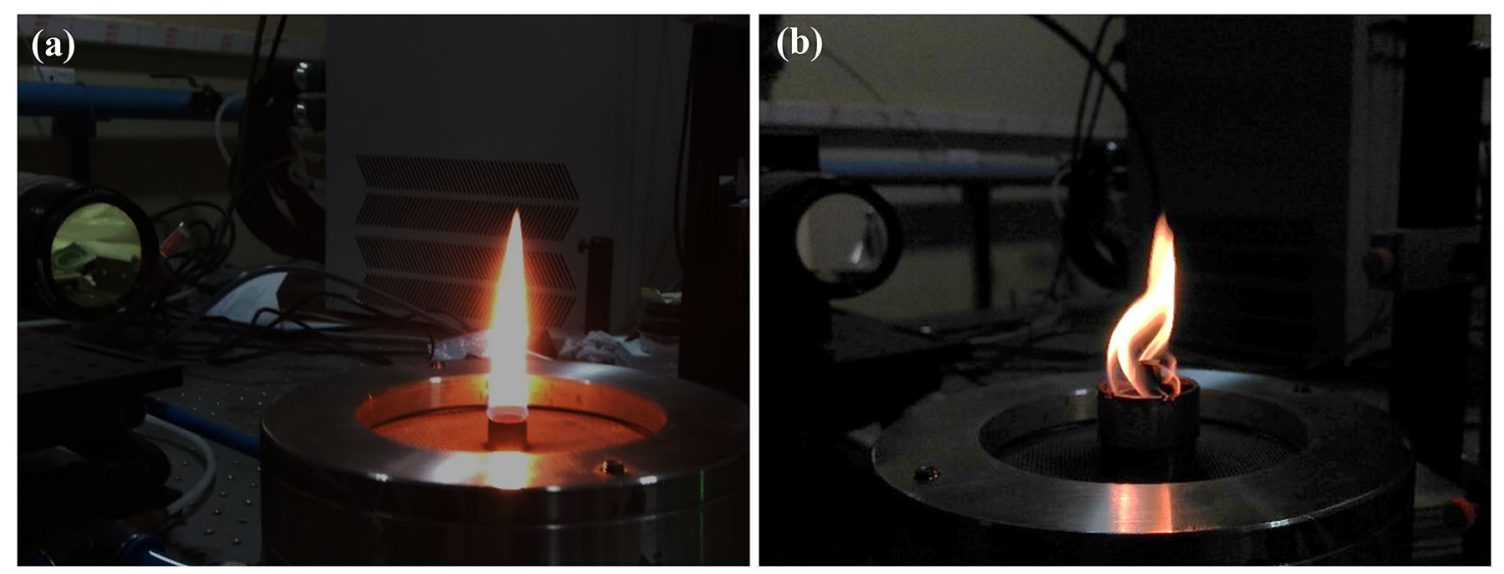

Fig. 6 Images showing actual photographs of $\mathbf{a}$ symmetric flame and $\mathbf{b}$ asymmetric flame 


\section{Only Soot-LII Sub and Processed Image}
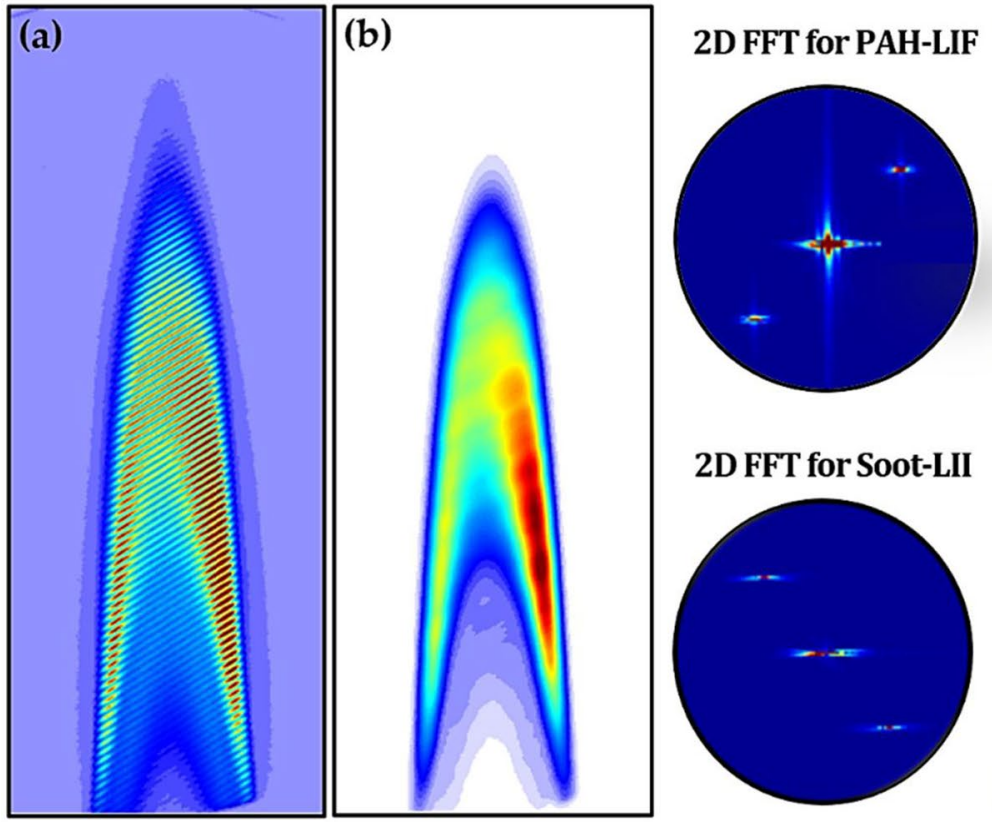

\section{D FFT for Soot-LII}

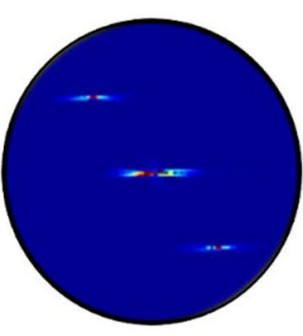

Only PAH-LIF Sub and Processed Image

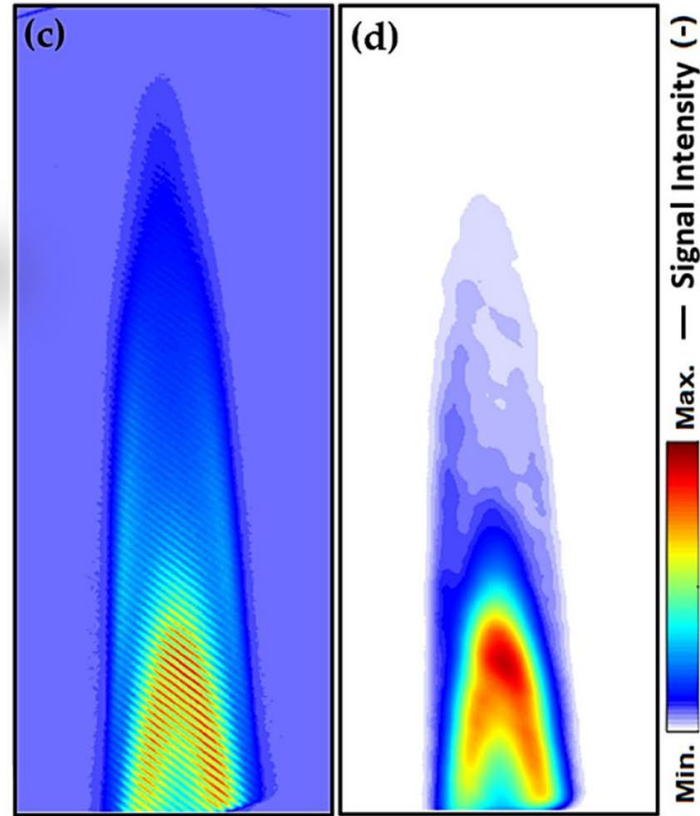

Fig. 7 a Averaged only Soot-LII raw image (cross patterned subimage) and c averaged only PAH-LIF raw image for a symmetric flame scan. b Processed averaged soot-LII extracted from (a), and d processed averaged PAH-LIF images extracted from (c). 2D FFT for both only soot-LII and only PAH-LIF are also given for comparison with FFT in Fig. 2
Acknowledgements National Centre for Combustion Research \& Development (NCCRD), Indian Institute of Science, Bangalore, India.

Funding Open Access funding enabled and organized by Projekt DEAL. This research was funded by the Ministry of Human Resource Development (MHRD), Govt. of India, under Scheme for Promotion of Academic and Research Collaboration (SPARC) proposal ID \#102.

\section{Declarations}

Conflict of interest The authors declare no conflict of interest.

Open Access This article is licensed under a Creative Commons Attribution 4.0 International License, which permits use, sharing, adaptation, distribution and reproduction in any medium or format, as long as you give appropriate credit to the original author(s) and the source, provide a link to the Creative Commons licence, and indicate if changes were made. The images or other third party material in this article are included in the article's Creative Commons licence, unless indicated otherwise in a credit line to the material. If material is not included in the article's Creative Commons licence and your intended use is not permitted by statutory regulation or exceeds the permitted use, you will need to obtain permission directly from the copyright holder. To view a copy of this licence, visit http://creativecommons.org/licenses/by/4.0/.

\section{References}

1. J.H. Kent, H.G. Wagner, Combust. Sci. Technol. 41, 245 (1984).

2. R.A. Dobbins, H. Subramaniasivam, in Soot Form. Combust. Mech. Model., ed. by H. Bockhorn (Springer, Berlin, 1994), pp. 290-301.
3. Z.A. Mansurov, Combust. Explos. Shock Waves 41, 727 (2005).

4. J. Kiefer, Z.S. Li, J. Zetterberg, X.S. Bai, M. Aldén, Combust. Flame 154, 802 (2008)

5. R.L. Gordon, A.R. Masri, E. Mastorakos, Combust. Flame 155 181 (2008)

6. X. Li, L. Ma, Combust. Flame 162, 642 (2015)

7. H.A. Michelsen, Proc. Combust. Inst. 36, 717 (2017)

8. R.K. Hanson, Symp. Combust. 21, 1677 (1988)

9. G. Kychakoff, P.H. Paul, I. van Cruyningen, R.K. Hanson, Appl. Opt. 26, 2498 (1987)

10. B. Yip, R.L. Schmitt, M.B. Long, Opt. Lett. 13, 96 (1988)

11. J. Hult, A. Omrane, J. Nygren, C. Kaminski, B. Axelsson, R. Collin, P.E. Bengtsson, M. Aldén, Exp. Fluids 33, 265 (2002)

12. R. Wellander, M. Richter, M. Aldén, Exp. Fluids 55, 1764 (2014)

13. K.Y. Cho, A. Satija, T.L. Pourpoint, S.F. Son, R.P. Lucht, Appl. Opt. 53, 316 (2014)

14. Y.N. Mishra, M. Koegl, K. Baderschneider, B. Hofbeck, E. Berrocal, C. Conrad, S. Will, L. Zigan, Appl. Opt. 58, 3775 (2019)

15. Y.N. Mishra, T. Tscharntke, E. Kristensson, E. Berrocal, Appl. Sci. 10, 1369 (2020)

16. R. Wellander, E. Berrocal, E. Kristensson, M. Richter, M. Aldén, Meas. Sci. Technol. 22, 125303 (2011)

17. T.R. Meyer, B.R. Halls, N. Jiang, M.N. Slipchenko, S. Roy, J.R. Gord, Opt. Express 24, 29547 (2016)

18. C.T. Foo, A. Unterberger, J. Menser, K. Mohri, Opt. Express 29, $244(2021)$

19. B.R. Halls, N. Jiang, T.R. Meyer, S. Roy, M.N. Slipchenko, J.R. Gord, Opt. Lett. 42, 2830 (2017)

20. B.R. Halls, P.S. Hsu, N. Jiang, E.S. Legge, J.J. Felver, M.N. Slipchenko, S. Roy, T.R. Meyer, J.R. Gord, Optica 4, 897 (2017)

21. T. Yu, F.J. Bauer, F.J. Huber, S. Will, W. Cai, Opt. Express 29, 5304 (2021)

22. L. Ma, Y. Wu, Q. Lei, W. Xu, C.D. Carter, Combust. Flame 166, 66 (2016) 
23. P.R. Medwell, P.A.M. Kalt, B.B. Dally, Combust. Flame 148, 48 (2007)

24. K.P. Geigle, W. O’Loughlin, R. Hadef, W. Meier, Appl. Phys. B Lasers Opt. 119, 717 (2015)

25. H. Zhao, N. Ladommatos, Prog. Energy Combust. Sci. 24, 221 (1998)

26. M. Röder, T. Dreier, C. Schulz, Appl. Phys. B Lasers Opt. 107, $611(2012)$

27. Z.S. Li, B. Li, Z.W. Sun, X.S. Bai, M. Aldén, Combust. Flame 157, 1087 (2010)

28. V.A. Fassel, J.M. Katzenberger, R.K. Winge, Appl. Spectrosc. 33, 1 (1979)

29. E. Berrocal, E. Kristensson, M. Richter, M. Linne, M. Aldén, Opt. Express 16, 17870 (2008)

30. Z. Li, J. Borggren, E. Berrocal, A. Ehn, M. Aldén, M. Richter, E. Kristensson, Combust. Flame 192, 160 (2018)

31. E. Kristensson, Z. Li, E. Berrocal, M. Richter, M. Aldén, Proc. Combust. Inst. 36, 4585 (2017)

32. Y.N. Mishra, P. Boggavarapu, D. Chorey, L. Zigan, S. Will, D. Deshmukh, R. Rayavarapu, Sensors 20, 1 (2020)

33. K. Dorozynska, E. Kristensson, Opt. Express 25, 5602 (2017)

34. A. Ehn, J. Bood, Z. Li, E. Berrocal, M. Aldén, E. Kristensson, Light Sci. Appl. 6, e17045 (2017)

35. K. Dorozynska, V. Kornienko, M. Aldén, E. Kristensson, Opt. Express 28, 9572 (2020)

36. V. Kornienko, E. Kristensson, A. Ehn, A. Fourriere, E. Berrocal, Sci. Rep. 10, 1 (2020)

37. S. Ek, V. Kornienko, E. Kristensson, Sci. Rep. 10(1), 1-10 (2020)

38. E. Kristensson, A. Ehn, J. Bood, M. Aldén, Proc. Combust. Inst. 35, 3689 (2015)

39. Y. Bao, K. Dorozynska, P. Stamatoglou, C. Kong, T. Hurtig, S. Pfaff, J. Zetterberg, M. Richter, E. Kristensson, A. Ehn, Plasma Sources Sci. Technol. 30, 04LT04 (2021)

40. M.J. Dyer, D.R. Crosley, Opt. Lett. 7, 382 (1982)

41. M. Tanahashi, S. Murakami, G.M. Choi, Y. Fukuchi, T. Miyauchi, Proc. Combust. Inst. 30, 1665 (2005)

42. K. Yamamoto, M. Takemoto, Environments 1, 42 (2014)

43. H.A. Michelsen, C. Schulz, G.J. Smallwood, S. Will, Prog. Energy Combust. Sci. 51, 2 (2015)

44. N. Palazzo, M. Kögl, P. Bauer, M.N. Mannazhi, L. Zigan, F.J.T. Huber, S. Will, Energies 12, 1993 (2019)
45. C.R. Shaddix, J.E. Harrington, K.C. Smyth, Combust. Flame 99, 723 (1994)

46. D.R. Snelling, K.A. Thomson, G.J. Smallwood, Ö.L. Gülder, Appl. Opt. 38, 2478 (1999)

47. S. Will, S. Schraml, A. Leipertz, Symp. Combust. 26, 2277 (1996)

48. B. Tian, Y. Gao, S. Balusamy, S. Hochgreb, Appl. Phys. B Lasers Opt. 120, 469 (2015)

49. R.L. Vander Wal, K.J. Weiland, Appl. Phys. B Laser Opt. 59, 445 (1994)

50. J. Yon, R. Lemaire, E. Therssen, P. Desgroux, A. Coppalle, K.F. Ren, Appl. Phys. B Lasers Opt. 104, 253 (2011)

51. N.E. Olofsson, J. Simonsson, S. Török, H. Bladh, P.E. Bengtsson, Appl. Phys. B Lasers Opt. 119, 669 (2015)

52. H. Chang, T.T. Charalampopoulos, Proc. R. Soc. Lond. Ser. A Math. Phys. Sci. 430, 577 (1990)

53. A. D’Alessio, A. Di Lorenzo, F. Beretta, C. Venitozzi, Symp. Combust. 14, 941 (1973)

54. B. Tian, Y. Gao, C. Zhang, S. Hochgreb, Combust. Flame 192, 224 (2018)

55. C.M. Sorensen, Aerosol Sci. Technol. 35, 648 (2001)

56. M.G.L. Gustafsson, W.W. Webb, Proc. Natl. Acad. Sci. U. S. A. 102, 13081 (2005)

57. E. Kristensson, Structured laser illumination planar imaging SLIPI applications for spray diagnostics, Ph.D. thesis, Lund university, 2012.

58. A.P. Kulkarni, D. Deshmukh, Appl. Phys. B Lasers Opt. 124, 1-9 (2018)

59. F.J. Bauer, K.J. Daun, F.J.T. Huber, S. Will, Appl. Phys. B Lasers Opt. 125, 1 (2019)

60. R.L. Vander Wal, Exp. Fluids 23, 281 (1997)

61. K. Hayashida, S. Nagaoka, H. Ishitani, Fuel 128, 148 (2014)

62. M.G.L. Gustafsson, J. Microsc. 198, 82 (2000)

63. R. Heintzmann, T.M. Jovin, C. Cremer, J. Opt. Soc. Am. A 19, 1599 (2002)

64. E. Berrocal, E. Kristensson, J. Manin, L. Araneo, M. Aldén, M. Linne, M. Richter, Opt. Express 19(14), 13647-13663 (2011)

Publisher's Note Springer Nature remains neutral with regard to jurisdictional claims in published maps and institutional affiliations. 